\title{
IMPORTÂNCIA DAS ATIVIDADES DE CAMPO NO ENSINO DA GEOGRAFIA E NA EDUCAÇÃO AMBIENTAL NO DESENVOLVIMENTO CONSCIÊNCIA CRÍTICA DO ALUNO
}

\author{
Viviane Alcântara ${ }^{1}$
}

\section{RESUMO}

As cidades brasileiras, nas últimas décadas, passaram por um crescente aumento da população urbana e intensificação de investimentos em infraestrutura com incremento da economia local. Todavia a intensificação desses processos causa repercussões no meio natural, isto é, no esgotamento dos recursos naturais. As práticas de ensino não ficam alheias a esta realidade, cada vez mais os educadores se utilizam de recursos didáticos para motivar os alunos à conscientização do espaço e das questões ambientais existentes no local onde vive. Para isso, a pesquisa em tela compartilha a experiência que está sendo vivenciada pelos alunos do quarto período do curso de Geografia da Universidade Salgado de Oliveira (Universo) da atividade de campo ao Parque Nacional da Tijuca. Propõe-se com esta atividade que o aluno compreenda melhor as relações existentes no espaço e desenvolva uma consciência crítica que o motiva a ter experiências e sensações prazerosas no aprendizado.

Palavras chave: Subjetividade, atividades de campo, educação ambiental.

\section{ABSTRACT}

In the last decades, the Brazilian's cities have passed by an increase in the urban population and intensification of investments in infrastructure to increase the local economy. However, intensifying of these processes cause repercussions in the nature, like exhaustion of the natural resources. The teaching's practices are not aliened to this reality, more and more educators are used to Environment Educational to motivate students to awareness of Space and Environmental Issues are on site, where they live. This article shares the experience which is doing with Geography's students of Salgado de Oliveira University (Universo) on field of activity the Tijuca National Park. Proposes to the students with this activity to understand different practices with the space and develop a critical consciousness that motivates you to have good experiences and sensations in the learning process.

Keywords: Subjectivity, field activities, environmental education.

\section{INTRODUÇÃO}

Cada vez mais as práticas de ensino da Geografia e também na Educação Ambiental se utilizam variados recursos como ferramentas para motivar os alunos ao aprendizado, indo além da educação formal. É disponibilizada ao professor uma enormidade de práticas: as aulas expositivas, as discussões e debates, as demonstrações, as aulas de laboratório e as atividades de campo. Todas têm como objetivo primordial garantir a pluralidade de formas de

\footnotetext{
${ }^{1}$ Mestre em População, Território e Estatísticas Públicas e Professora do Departamento de Geografia da Universidade Salgado de Oliveira. E-mail: vialcantara@gmail.com
} 
construir o conhecimento, isto é, fornecer subsídios para que o aluno compreenda o tema a ser estudado em vários contextos.

Os sentimentos e as emoções são amplamente analisados no âmbito da psicologia (PIAGET, 2001; VYGOTSKY, 1998) e cada vez mais os estudiosos da Educação evidenciam o uso da motivação do aluno e dos sentimentos positivos no processo de aprendizagem (SENECIATO e CAVASSAN, 2004).

Tal aprendizado tem como objetivo formar educandos cidadãos conscientes, pessoas autônomas com senso crítico, sendo capazes de exercer a sua cidadania e questionar a ordem social e econômica vigente.

Na relação pedagógica, a autonomia está associada ao reconhecer no outro a capacidade de participar, ter o que oferecer e poder decidir aliado ao potencial do sujeito em "tomar para si” sua própria formação. Conforme a discussão de Pretti (2000) entende-se que a autonomia está relacionada ao próprio indivíduo, à sua capacidade de buscar por si mesmo, sem uma dependência explícita de outrem. Neste aspecto reconhecer a "autonomia" no processo de ensino e de aprendizagem, significa entender que o outro é independente.

"Vivemos um tempo da razão instrumental técnica. A técnica vem para substituir o objeto em corpo e alma" (PIMENTEL e TANCMAN, 2014). O lazer, como veículo de educação, valoriza os aspectos subjetivos e transcende a apropriação do conhecimento pelo raciocínio-lógico, que é mais valorizado na educação formal.

O presente trabalho pretende apresentar uma proposta de atividade de campo ao Parque Nacional da Tijuca (PNT) que está sendo realizada com os alunos da disciplina de Gestão e Planejamento Ambiental do curso de Geografia (licenciatura) da Universidade Salgado de Oliveira (Universo).

A escolha do PNT se deve por este apresentar a Mata Atlântica, bioma característico da região e também por sofrer pressões do processo desordenado de urbanização da cidade do Rio de Janeiro. Permitindo ao aluno analisar criticamente seu entorno.

O artigo está estruturado em seis seções. A primeira seção é esta, uma introdução ao tema. A segunda parte é a revisão bibliográfica, apresenta os principais conceitos que salientam a importância da atividade de campo. A terceira seção apresenta a metodologia que está sendo utilizada com os alunos do curso de graduação em Geografia. A quarta seção apresenta os primeiros resultados. A quinta seção apresenta conclusões cabíveis e os desafios dessa metodologia e desdobramentos futuros e a última seção é destinada aos agradecimentos.

\section{EDUCAÇÃO AMBIENTAL E ATIVIDADE DE CAMPO}

A Lei Federal 9.795, de abril de 1999, institui a Política Nacional de Educação Ambiental e define a define como:

"processos por meio dos quais o indivíduo e a coletividade constroem valores sociais, conhecimentos, habilidades, atitudes e competências voltadas para a conservação do meio ambiente, bem de uso comum do 
povo, essencial à sadia qualidade de vida e sua sustentabilidade" (BRASIL, 1999).

Essa lei foi a base para a resolução ${ }^{0} 2$ de junho de 2012, que estabeleceu as Diretrizes Curriculares para a educação ambiental, que tem como objetivo estruturar as práticas relacionadas a educação ambiental de forma a torná-la interdisciplinar desde a educação infantil ao ensino superior.

Medina (2001) afirma que a educação ambiental deve ser vista como um processo que permite:

"a compreensão crítica e global do ambiente, para elucidar valores e desenvolver atitudes que lhes permitam adotar uma posição consciente e participativa a respeito das questões relacionadas com a conservação e a adequada utilização dos recursos naturais" (MEDINA, 2001).

Desta forma se constata que a educação ambiental é visão sistêmica e não fragmentada do ambiente, que promove a consciência ambiental e uma percepção crítica das ações e práticas que degradam a natureza.

A degradação do espaço natural provoca riscos na qualidade de vida dos seres humanos e nas suas práticas econômicas. Deslizamento de encostas e enchentes ocasionam diversos prejuízos sociais econômicos e sociais nas cidades brasileiras. A consciência ecológica é uma necessidade para a sociedade atual e esta é desenvolvida dentro da educação ambiental. Machado (1982) afirma que só se cuida daquilo que se conhece.

A atividade de campo é uma prática de ensino disponível para os educadores, em especial aqueles que têm o espaço como objeto de estudo. Associada com outras atividades, tais como aulas expositivas na sala, permitem a exploração de conteúdos, de sentimentos e atitudes que enriquecem o aprendizado.

Os Parâmetros Curriculares Nacionais (PCN) definem a atividade de campo como uma "excursão ou estudo do meio", uma "modalidade de busca de informações em fontes variadas" (BRASIL, 1998).

Harlen (1989) afirma que as atividades desenvolvidas fora da escola funcionam como suplemento aos temas já debatidos na sala de aula ou incentivar os alunos, a ampliarem o aprendizado com estudos posteriores.

Fernandes (2007) enfatiza que a atividade de campo é toda a tarefa que promove a saída do aluno da escola. Viveiro e Diniz (2009) afirmam que é uma estratégia de ensino em que se substitui a sala de aula por outro espaço, que pode ser natural ou não. E este espaço permite estudar as relações produzidas pelos seres vivos, isto é, as relações sociais, econômicas, culturais, e naturais.

No cenário internacional, Field Studies Council of Britain desenvolveu uma série de trabalhos de campo numa perspectiva educacional. E foi no movimento Escola Nova que os trabalhos de campo ganharam status de proposta pedagógica e se tornaram importantes no processo educacional. 
No Brasil, Silva e Neto (2007) apontam resultados positivos nas idas de turistas as unidades de conservação Parque Municipal do Mindu e Jardim Botânico de Manaus Adolfo Ducke, principalmente no que tange ao aprendizado e a sensibilização para as questões ambientais.

Cavassan e Seniciato (2008) relatam que ao levar as turmas de sexta série do ensino fundamental ao Jardim Botânico Municipal de Bauru tiveram como resultado a afetividade e a motivação dos educando para a construção do conhecimento. Assim, dentre as vantagens do trabalho de campo se destacam:

- O trabalho de campo permite o contato direto do aluno com o ambiente natural. A interação do corpo para explorar os lugares permite a análise, a reflexão, fazendo com que o educando tenha maior capacidade de aprender e reter as informações.

- A atividade de campo permite que o aluno se "sinta" o protagonista do seu ensino, sendo um elemento ativo e não apenas um receptor de conhecimento.

- Permite que o educando amplie seus relacionamentos sociais, em especial com o professor e com os demais da turma. O companheirismo resultante da experiência em comum e da convivência agradável entre os sujeitos antes, durante e depois da atividade.

Viveiro e Diniz (2009) afirmam que a atividade de campo proporciona uma motivação intrínseca e extrínseca no educando. Esta é a motivação em atender as propostas pelo professor mediante a atividade, enquanto que aquela é explorar, esmiuçar os conhecimentos recentemente adquiridos.

Lopes e Allain (2002) sinalizam que o educador deve ter objetivos bem delimitados e estar qualificado para tal tarefa, ou seja, conhecer muito bem o local da visita. Uma vez que a quantidade de fenômenos e de processos ocorre de forma concomitante no ambiente a ser visitado que podem confundir os educandos na assimilação dos conhecimentos.

Logo, constata-se que a atividade de campo não é apenas uma saída, mas ela inclui fases de planejamento (definição de objetivos, de conteúdos a serem assimilados, dos custos envolvidos, da duração da atividade, da localização e etc.), execução (a saída propriamente dita), exploração dos resultados (coleta e análise de dados, debate e retomada de antigos conteúdos) e avaliação (verificando se a atividade correspondeu aos objetivos a priori).

\section{PARQUE NACIONAL DA TIJUCA}

O Parque Nacional da Tijuca (PNT) foi criado em julho de 1961, é uma Unidade de Conservação federal que compreende uma área de aproximadamente $33 \mathrm{~km}^{2}$ de Mata Atlântica. Devido a biodiversidade de fauna e flora, recebe anualmente 3 milhões de visitantes por ano segundo dados da ICMBio.

A escolha do PNT se deve pelos seguintes fatores: 
1- É um parque que sofre muitas pressões pelo crescimento urbano desorganizado do seu entorno, principalmente dos aglomerados subnormais - favelas (Figura 1).

2- Por ser próximo da universidade, faz com que o educando se identifique com a realidade vivenciada.

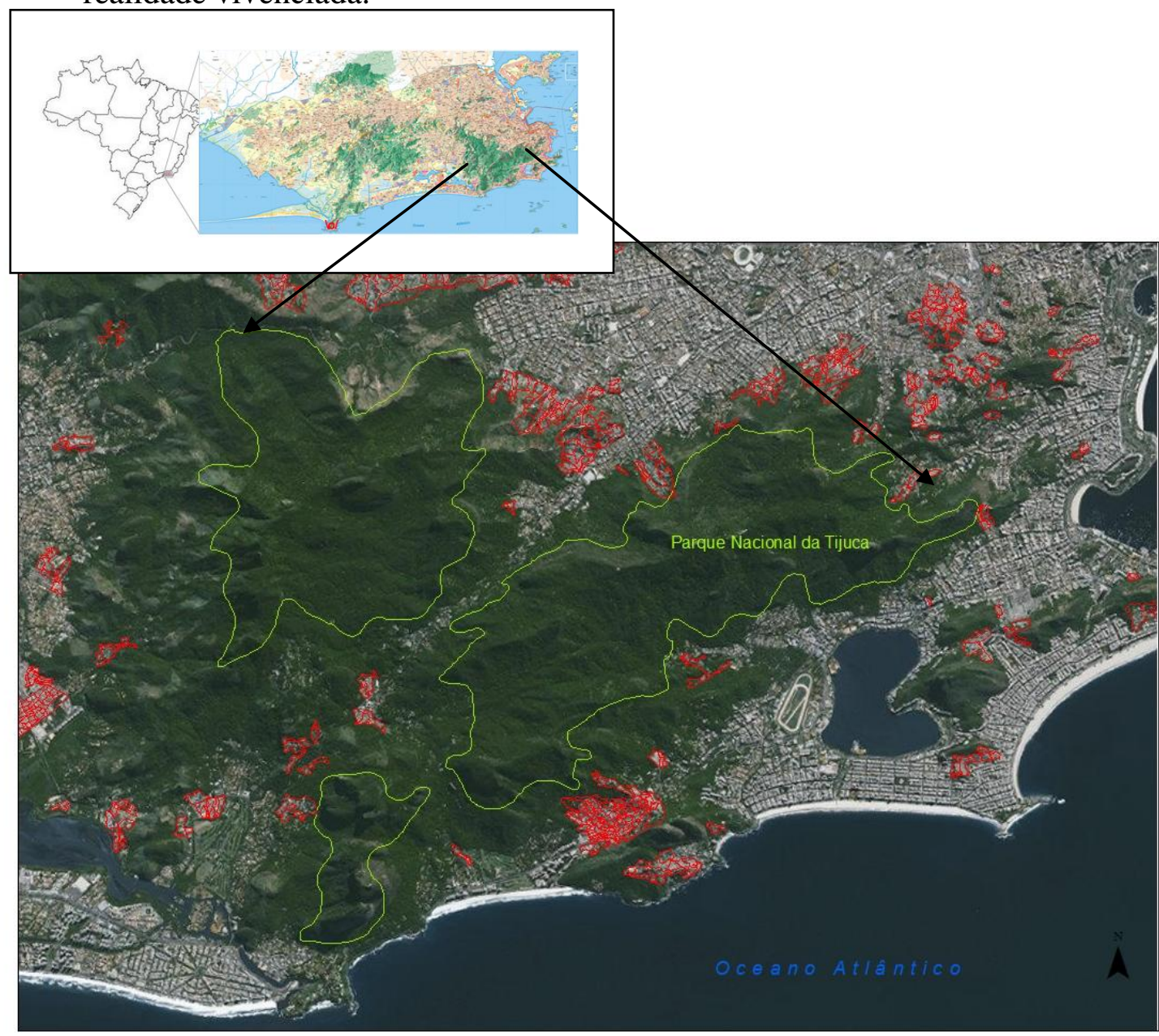

Figu

ra 1: Parque Nacional da Tijuca e seu entorno. As manchas em vermelho identificam os aglomerados subnormais que muito dos casos adentram aos limites do Parque.

\section{METODOLOGIA}

A metodologia está dividida em três etapas, que foram explicadas aos alunos e são descritas a seguir:

\section{$1^{\text {a }}$ Etapa: Exposição, em sala de aula, dos conceitos relacionados à degradação ambiental em espaços urbanos}

Para isso foi proposto aos alunos à leitura e o debate de textos relacionados à pegada ecológica e também o cálculo. Tudo disponível no link: < http://www.wwf.org.br/natureza_brasileira/especiais/pegada_ecologica/sua_pegada/> 
A pegada ecológica foi proposta pelos William Rees e Mathis Wackernagel que procuravam formas de medir essas repercussões no meio físico e, em 1996, elaboraram uma metodologia de contabilidade ambiental que avalia a pressão do consumo das populações humanas sobre os recursos naturais.

1) Ela permite comparar diferentes padrões de consumo e verificar se estão dentro da capacidade ecológica do planeta. Expressada em hectares globais (gha), permite comparar diferentes padrões de consumo e verificar se estão dentro da capacidade ecológica do planeta. Um hectare global significa um hectare de produtividade média mundial para terras e águas produtivas em um ano.

O debate teve como objetivo motivar ao educando os sentimentos e emoções subjetivas de pertencimento ao espaço que vive.

\section{$2^{\text {a }}$ Etapa: Visita ao Parque Nacional da Tijuca}

A visita é feita em um dia de aula, a fim de que todos tenham a oportunidade de realizar a atividade. É conhecida a sede do parque e assistido os vídeos sobre a instituição do PNT e os diferentes conflitos sociais e econômicos que ocorrem na floresta. Depois, é percorrida uma pequena trilha em que são observados os processos naturais que ocorrem naquela área.

Esta atividade tem como objetivo despertar no aluno a busca por mais conhecimento dos processos naturais e ambientais que ocorrem no ecossistema da Mata Atlântica.

No fim da visita é distribuído aos alunos um questionário-base que abordam aspectos dos processos erosivos, do tipo de vegetação e fauna local e a identificação das diferentes pressões sofridas na mata que a impactam de forma negativa.

\section{$3^{\text {a }}$ Etapa: Entrega do relatório e verificação dos conhecimentos}

Nesta etapa, novamente em sala de aula, os educandos apresentam o relatório sobre suas impressões da atividade de campo. É previsto também o desenvolvimento de reflexões com todos os alunos sobre a tarefa e quais as conclusões cabíveis.

\section{RESULTADOS}

Até o fechamento deste artigo apenas a etapa um foi concluída. Todavia, verifica-se o êxito de toda a proposta de atividade de campo ao Parque Nacional da Tijuca.

Todos os educandos se espantaram com o resultado da sua pegada ecológica e apontaram medidas de redução para reduzir o impacto da sua ação no meio ambiente. Também conseguiram identificar no entorno de sua casa, nas proximidades do trabalho e da universidade atividades sociais e econômicas que degradam o meio ambiente.

\section{CONCLUSÃO}

A associação de aulas expositivas com outras ferramentas de ensino auxiliam a motivar os alunos para o processo de assimilação de conceitos teóricos, a reflexão e a análise 
do espaço. O ganho desta metodologia é que ela torna o ensino uma aventura, fazendo com que sentimentos positivos estejam associados ao ensino e possibilitem uma educação mais efetiva.

Uma das dificuldades que pode ocorrer é a ausência do educando em uma das etapas que poderá acarretar prejuízo no desenvolvimento cognitivo do aluno.

Para trabalhos futuros se propõe a transversalidade com outras disciplinas do curso de graduação em Geografia, tais como biogeografia, cartografia, geologia e etc. Isso proporcionará aos graduandos maior interação com temas próprios da geografia e a sua respectiva assimilação.

\section{AGRADECIMENTOS}

A autora gostaria de agradecer à Universidade Salgado de Oliveira (Universo) pela oportunidade de realizar esta prática de ensino e ao Grupo de Pesquisa CNPq Tecnologias de comunicação e informação no mundo contemporâneo que possibilitam o desenvolvimento de estudos nesta área.

\section{BIBLIOGRAFIA}

BRASIL. Parâmetros Curriculares Nacionais: terceiro e quarto ciclos do ensino fundamental: Ciências Naturais. Brasília: MEC/SEF, 1998.

FERNANDES, J. A. B. Você vê essa adaptação? A aula de campo em ciências entre o retórico e o empírico. São Paulo, 2007. 326p. Tese (Doutorado em Educação) - Faculdade de Educação, Universidade de São Paulo, São Paulo, 2006.

FERREIRA, A. R \& ROSSO, A. J. Educação ambiental na escola: a visão dos professores e professoras de ciencias e biologia acerca da formação necessária. In: Seminário Internacional "Experiências da Agenda 21: Os desafios do nosso tempo. Paraná: Novembro de 2009. Disponível no link: <

http://www.eventos.uepg.br/seminariointernacional/agenda21parana/trabalho_cientifico/Traba lhoCientifico016.pdf $>$ Acesso em maio de 2015.

HARLEN, W. Enseñanza y aprendizaje de las ciencias. Tradução de Pablo Manzano. Madrid, Morata, 1989. Título original: Teaching and learning primary science. (Colección Pedagogía. Educación infantil y primaria).

LIBÂNEO, J. C. Didática. São Paulo: Cortez, 1994. (Coleção Magistério $2^{\circ}$ Grau. Série Formação do Professor)

LOPES, G. C. L. R. \& ALLAIN, L. R. Lançando um olhar crítico sobre as saídas de campo em biologia através do relato de uma experiência. In: VIII ENCONTRO PERSPECTIVAS DO ENSINO DE BIOLOGIA, 6, 2002, São Paulo. Anais... São Paulo: FEUSP, 2002. 1 CD-ROM.

MACHADO, A. B. M. Conservação da natureza e educação. In: CONGRESSO NACIONAL SOBRE ESSÊNCIAS NATIVAS, 1982, Campos do Jordão. Anais... Campos do Jordão: [s.n.], 1982. p. 109-108. 
MEDINA, N. M. A formação dos professores em Educação Fundamental. In: MEC; SEF, Panorama da educação ambiental no ensino fundamental / Secretaria de Educação Fundamental - Brasília, 2001. 149 p

PIMENTEL, E.M \& TANCMAN, M.C.S. A Geografia e a influência das imagens e do imaginário na questão ambiental. In Meio ambiente e meio urbano. Org. PIMENTEL, E. M. Niterói, 2015 (No Prego) 110 p.

PIAGET, J. Seis estudos de psicologia. 24. Ed. Rio de Janeiro: Forense Universitária. 2001. 136p.

SENICIATO, T.; CAVASSAN, O. Aulas de campo em ambientes naturais e aprendizagem em ciências- um estudo com alunos do ensino fundamental. Revista Ciência e Educação, 2004. Vol. 10 (1) p. 133 - 147. Disponível no link: < http://www.scielo.br/pdf/ciedu/v10n1/10.pdf. > Consulta maio de 2015.

A Afetividade, motivação e construção de conhecimento científico nas aulas desenvolvidas em ambientes naturais. Revista Ciência e Cognição, 2008. Vol. 13 (3) p. 120 - 136. Disponível no link: < http://www.cienciaecognicao.org. > Consulta maio de 2015.

SILVA, N. P. de S. \& NETO, A. R. da C. A educação ambiental como instrumento de sensibilização turística em Unidades de Conservação. Revista Eletrônica Aboré. Publicação da Escola Superior de Artes e Turismo. Ed. 03/2007. Disponível no link: < http://www.revistas.uea.edu.br/old/abore/comunicacao/comunicacao pesq 3/Nathalin\%20Priscila\%20 de\%20Souza\%20da\%20Silva.pdf. > Consulta maio de 2015.

VIGOTSKI, L. S. O desenvolvimento psicológico na infância. São Paulo: Martins Fontes, 1998. $326 \mathrm{p}$.

VIVEIRO, A. A. \& DINIZ, R. E. da S. Atividades de campo no ensino das ciências e na educação ambiental: refletindo sobre as potencialidades desta estratégia na prática escolar. Ciência em tela. Vol. 2, $\mathrm{n}^{\mathrm{o}} 1$. 2009. Disponível no link: < http://www.cienciaemtela.nutes.ufrj.br/artigos/0109viveiro.pdf.> Consulta em abril de 2015. 